\title{
Structure Checking Computations of Sound Barrier Design
}

\author{
Yan Li \\ School of architecture and civil engineering ,Chengdu university 610106 China \\ 22328029@QQ.com
}

Keywords: traffic noise, sound barrier, structure design, durability .

Abstract. With the development of road construction, traffic noise pollution becomes more and more serious. Sound barrier, an effective and comparatively inexpensive measure of controlling noise, will be developed to some degree. The sound barrier durability is a very complicated problem. It is influenced by structure design, concrete construction and so on.

\section{Introduction}

With the development of the national economy and social production, traffic has been expanded and the number of vehicle has seen a rapid increase. Traffic pollution is more and more serious, which in some way, is definitely caused by the construction of city light rail and intercity passenger dedicated line. Noise pollution has become one of the four public hazards in China urban environment issue, in parallel with water pollution, waste pollution, and air pollution[1]. Noise annoys and distracts human beings, diminishes efficiency and is hard to eliminate.

\section{Sound Barrier Mechanism}

Nowadays the complaint about noise accounts for $1 / 2$ of the total pollution complaint. In a rather long time, people are always taking measures to reduce traffic noise and try hard to make it bearable. The sound barrier is an acoustic baffle set between the noise source and the protected area (the sensitive point). It is one of the important measures controlling local noise pollution in an open space in workplaces. Its function is to block the direct sound from the sound source to the sound receiving point, to put the protected buildings and environment in the shadow zone.

When the acoustic wave from the noise source comes across the sound barrier, it will transmit along three routes (as shown in fig.1). Some arrives the position across barrier and the rest wave is reflected in the war surface of the sound barrier. The insertion loss of the sound barrier is mainly decided by sound energy distribution of the three routes[2].

According to the law of conversation of energy:

$E_{0}=E_{r}+E_{\alpha}+E_{\tau}$

$E_{0}$ - the incident total acoustic energy to components in unit time

$E_{\gamma}$-reflected acoustic energy

$E_{\alpha}$-acoustic energy absorbed by components

$E_{\tau}$ - acoustic energy through components

The sound level difference between the direct and diffracted sound is called a diffracted sound attenuation, which is the primary physical quantity that decides the sound barrier insertion. 


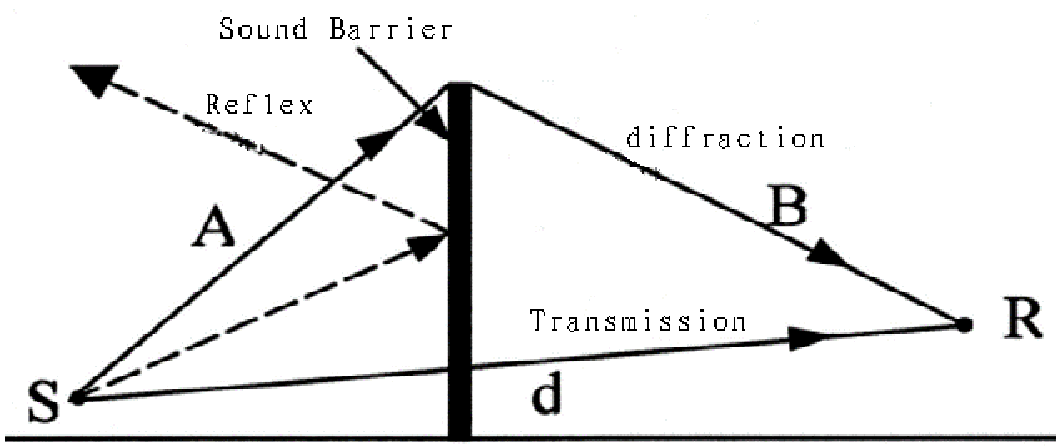

Fig.1 Acoustic Propagation

\section{Force Analysis of Sound Barrier}

The sound barrier has been set on the highway, railway and urban overpass in our country. But the barrier is to be damaged by various acts several years later after construction. Not only will the road appearance be affected negatively, but also the noise reduction effect will be influenced terribly. The main reason of such damage is the imperfect structure design of the sound barrier[3]. Under ordinary circumstances, the structure design of sound barrier consists of two parts: one is load-bearing structure's design and calculating, which focus on the strength and stiffness of the barrier; the other is that the structure must meet the structural requirements.

Principle load on the sound barrier are:

(1)Vertical permanent load by material forces, which is decided by the actual weight of the sound barrier's material.

(2)The wind load on the sound barrier. One can value according to Building Structure Design Codes or calculate on the basis of the once-in-a-century maximum wind velocity in a certain region.

Relationship between wind velocity and wind pressure:

$w_{0}=\frac{v^{2}}{16}$

$v$-wind velocity

$w_{0}$-basic wind pressure

Wind pressure on the sound barrier:

$w=k_{1} k_{2} k_{3} k_{4} w_{0}$

$k_{1}$ - a structural constant; on large and medium-sized bridges and highways and secondary roads, the value is 1 ; others 0.85

$k_{2}$-wind vibration coefficient value of 1.3

$k_{3}$-wind pressure height coefficient, as shown in table 1

$k_{4}$-topographic features factor, as shown in table 2

Table 1 Wind Pressure Height Coefficient

\begin{tabular}{|c|c|c|c|c|c|c|c|c|c|}
\hline height $(\mathrm{m})$ & 20 & 30 & 40 & 50 & 60 & 70 & 80 & 90 & 100 \\
\hline $\mathrm{K}_{3}$ & 1 & 1.13 & 1.22 & 1.3 & 1.37 & 1.42 & 1.47 & 1.52 & 1.66 \\
\hline
\end{tabular}

Table 2 Topographic Features Factor

\begin{tabular}{|c|c|c|c|c|c|}
\hline $\begin{array}{c}\text { Topographic } \\
\text { feature }\end{array}$ & $\begin{array}{c}\text { General } \\
\text { zone }\end{array}$ & $\begin{array}{c}\text { Mountain basins } \\
\text { and valleys }\end{array}$ & $\begin{array}{c}\text { Yamaguchi } \\
\text { Canyonlands }\end{array}$ & $\begin{array}{c}\text { Downtown } \\
\text { shelter points }\end{array}$ & $\begin{array}{c}\text { Coast and } \\
\text { inlands }\end{array}$ \\
\hline$k_{4}$ & 1 & $0.75 \sim 0.85$ & $1.2 \sim 1.4$ & 0.8 & $1.3 \sim 1.5$ \\
\hline
\end{tabular}




\section{The Monomer Component Strength Checking Calculation of Sound Barrier}

Generally sound barriers are made a certain amount of monomers in advance and assembled on side, to ensure that the sound barrier has enough strength and rigidity in transportation and installation. Forces of monomers differ between transportation and installation and operation, so the whole process should cause enough attention[4]. The strength and rigidity of the monomers after installation is mainly decided by the bending strength and deformation under the horizontal wind pressure and the spaces of columns also matters. The strength and stiffness in transportation and installation are considered mainly for bending and deformation under gravity. In addition, the location of support points in transportation and lifting points in hoisting should apply for the requirement strictly, in order to reduce the deformation or even the damage of the sound barrier in transportation and operation.

\section{The Load-bearing Structure Checking Computations}

The structure of the sound barrier is generally made of the following parts: columns, baffle and column connections, column and base connections, (The base of road viaduct is often the road viaduct itself.) and base. Besides, on the ground, there are shadow base, pile base and other categories.

Selection of a calculated cell: taking a representative of half the vertical spacing around the adjacent column for a calculated cell, as the shaded part shows in fig.2.

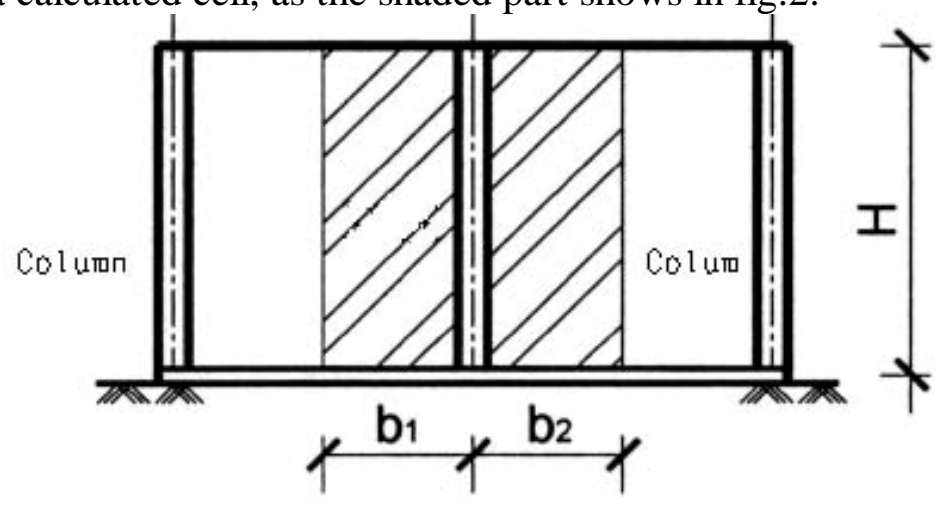

Fig.2 A Calculating Cell

The wind load of the sound barrier is an important factor affecting the stability of the barrier. Its forth transmission path on sound barriers is: horizontal wind load, columns, base, and at last subgrade. Strength Checking Computations

1) Column horizontal wind load, which is mainly transmitted from the baffle

$q=w\left(b_{1} b_{2}\right) \quad(4)$

$q$-the average horizontal load on columns

$w$-wind load, calculated by the formula (3)

$b_{1}, b_{2}$-half distance from two adjacent columns to a certain column in-between

2) Column vertical wind load

$N=G_{1}+G_{2}$

$G_{1}$ - gravity of the column

$G_{2}$ - gravity of the baffle in a calculating unit

The column will be under all the wind load produced by the sound barrier's horizontal wind pressure. Generally, the column makes up a single outrigger form. Therefore, the selection connecting the column and the base is the most dangerous cross-section for a column.

3) Calculations

$\mathrm{M}$ - the bending moment of a column under horizontal load

$\mathrm{N}$-vertical press from the gravity of a column

$\mathrm{V}$-shearing force

As is shown in fig.3: 


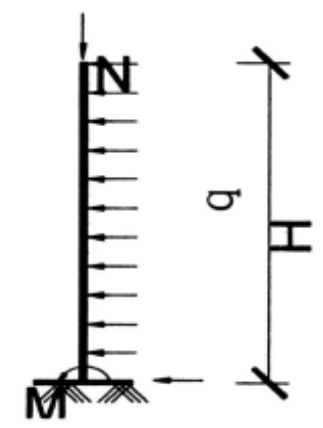

Fig.3 Stress Analysis of the Column

$\mathrm{N}$ - the bearing stress of the section

Bending moment:

$M=\frac{1}{2} q H^{2}=\frac{1}{2}\left[w\left(b_{1}+b_{2}\right)\right] H^{2}$

Shearing force:

$V=q H=\left[w\left(b_{1}+b_{2}\right)\right] H$

If allowable stress design method is used, then according to the third strength theory (The column of sound barriers belongs to plastic material for steel is usually used.) one can get:

$\sqrt{\sigma^{2}+4 \tau^{2}} \leq[\sigma]$

$\sigma$-the maximum stress of column control section

$\sigma=\frac{M y}{I}+\frac{N}{A}$

I-inertia selection moment of column control section

$\mathrm{Y}$-distance from outside of the control selection to neutral axis

A - the column area of control section

$\tau$-shearing stress of control section

$\sigma=\frac{v}{A} ; \quad[\sigma]$-allowable stress of the column

\section{Stiffness Computations}

The top displacement of a column should be less than 1/3000 and this has an immediate connection with the section rigidity of the column. The cantilever under average wind load can be known according to Material Mechanics and Structural Mechanics. And on the basis of graphic multiplication method, the top displacement of a column is:

$\Delta=\frac{1}{E I} \times \frac{1}{3} H \times \frac{1}{2} q H^{2} \times \frac{3}{4} H=\frac{1}{8 E I} q H^{2}$

$\mathrm{E}$ - the elastic modulus of column materials

I- the inertia moment of the column control interface

Generally, the displacement should be coincidence with the following formula:

$$
\frac{\Delta}{H} \leq \frac{1}{300}
$$

If the displacement fails to meet the above requirement, the section area should be increased while the spaces should be reduced to meet the needs of section force.

\section{Computations of the Connection Between the Column and Base}

The base of sound barriers is usually the crash barrier when barriers are constructed on the viaduct. When the new buildings are constructed, people tend to embed the flange to connect the column with the base. And when the buildings are remodeled, people tend to fix the column with fasteners by means 
of the outside part of railing panels. People should make sure that the embedded part has an enough anchorage length when using the flange, in order that the column has sufficient tensile and shear strength[5].

The column and the base are often connected with the foundation bolt. And when calculating people should consider that the foundation bolt is under the stress of both tensile and shear strength.

$$
\begin{aligned}
& \sqrt{\left(\frac{N_{v}}{N_{v}^{b}}\right)^{2}+\left(\frac{N_{t}}{N_{t}^{b}}\right)^{2}} \leq 1 \quad(11) \\
& N_{v}^{b}, N_{t}^{b} \text {-the design value of tensile and shear strength on a bolt screw } \\
& N_{v} 、 N_{t} \text {-the design value of tensile and shear strength on a bolt } \\
& N_{v}=\frac{v}{n} \quad n \text {-the number of bolts } \\
& N_{t}=\frac{N}{n}+\frac{M y_{1}}{\sum y_{i}^{2}} \quad y_{i} \text {-the distance from No. i bolt to rotation axis }
\end{aligned}
$$

The strength and stability of components can be ensured after the calculation, but the perfection of operation acts not that definite. For example, the compactness of board and board and that of column and board in a sound barrier will be guaranteed only when structural section is combined properly, by which leakage noise can be avoided as much as possible so that sound insulation property of barriers will not be affected.

\section{Conclusion}

The sound barrier is widely used, with the mushroom of the highway and the construction of express railways. Structure checking computations of sound barrier is a necessary condition to ensure the barrier's security, an important method to improve the durability, and the key point of structural design.

\section{Acknowledgements}

This paper is based on the philosophy and social science planning project of Chengdu, the project name: the study of the fuzzy mathematics comprehensive evaluation method in the evaluation of underground space utilization in Chengdu City . Project code: 2016z30

\section{Reference}

[1]Chen Zhenfan. Principles of steel structure design[M].Beijing:Science Press.

[2]BG50017-2003.Code for design of steel structures[S]

[3]Cui Jia. Understanding and application of steel structure design code[M]. Beijing: China Building Industry Press.

[4]Specification for acoustical design and measurement of noise barriers[S].State Environmental Protection Administration

[5]Ma Daqiu. Handbook of vibration and noise control [M]. Beijing: Machinery Industry Press 